\title{
НАНОЧАСТИЦЫ НА ОСНОВЕ ГИДРОКСИАПАТИТА И ПОРФИРИНФУЛЛЕРЕНА ДЛЯ ДИАГНОСТИЧЕСКОГО И ТЕРАПЕВТИЧЕСКОГО ПРИМЕНЕНИЯ ПАРАМАГНИТНЫХ ИОНОВ И РАДИОНУКЛИДОВ
}

\author{
М. А. Орлова ${ }^{1,2}$, А. Л. Николаев ${ }^{1}$, Т. П. Трофимова ${ }^{1,3}$, А. П. Орлов ${ }^{1}$, А. В. Северин ${ }^{1}$, С. Н. Калмыков \\ Химический факультет, Московский государственный университет имени М. В. Ломоносова, Москва \\ 2 Отдел биохимии и фармакологии, \\ Национальный медицинский исследовательский центр детской гематологии, онкологии и иммунологии имени Д. Рогачева, Москва \\ ${ }^{3}$ Институт физиологически активных веществ РАН, Черноголовка
}

\begin{abstract}
Использование наночастиц как носителей лекарственных средств широко изучается. Одним из важных вопросов остается изменение размеров и цитотоксических свойств частиц в процессе их получения и применения. Целью

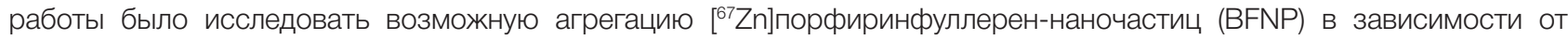
времени и провести сравнительный анализ свойств наночастиц гидроксиапатита (НАР), полученных различными способами. Оказалось, что агрегация BFNP качественно не влияет на функцию наночастиц, но количественно уменьшает их воздействие на лейкемические клетки. Варьирование способов получения и обработки наночастиц НАР позволяет менять их форму, размеры и сорбционную способность по отношению к ионам металлов, а также лигандам и комплексам. Используя ферментативный метод, мы получили НАР с заранее заданными свойствами путем варьирования условий синтеза. Полученные наночастицы НАР представляют собой радиопрепараты, содержащие короткоживущие изотопы цинка и меди (в виде ионов и соединений - производных тиазина и пиримидина). Эти наноконструкции содержат два антиопухолевых компонента (радионуклид и лиганд или комплекс), что определяет их фармакологический потенциал для диагностики и лучевой терапии.
\end{abstract}

Ключевые слова: гидроксиапатит, порфиринфуллерен, производные тиазина и пиримидина, HL-60, K-562, MOLT-4, радионуклиды цинка и меди

$\checkmark$ Для корреспонденции: Марина Алексеевна Орлова

Ленинские горы, д. 1, стр. 3, г. Москва, 119992; orlova.radiochem@mail.ru

Статья получена: 27.06.2018 Статья принята к печати: 20.09.2018

DOI: $10.24075 /$ vrgmu.2018.075

\section{HYDROXYAPATITE AND PORPHYRIN-FULLERENE NANOPARTICLES FOR DIAGNOSTIC AND THERAPEUTIC DELIVERY OF PARAMAGNETIC IONS AND RADIONUCLIDES}

\author{
Orlova MA ${ }^{1,2}$, Nikolaev $A L^{1}$, Trofimova $\mathrm{TP}^{1,3}$, Orlov $\mathrm{AP}^{1}$, Severin $A V^{1}$, Kalmykov $\mathrm{SN}^{1}$ \\ Faculty of Chemistry, Lomonosov Moscow State University, Moscow \\ Department of Biochemistry and Pharmacology, \\ Dmitry Rogachev National Medical Research Centre of Hematology, Oncology and Immunology, Moscow \\ ${ }^{3}$ Institute of Physiological Active Compounds of RAS, Chernogolovka
}

Nanoparticles for drug delivery are the subject of extensive research. Importantly, they can transform in size during synthesis or actual use, thereby changing their cytotoxic properties. The aim of the present work was to study the tendency of [ $\left.{ }^{67} \mathrm{Zn}\right]$ porphyrin-fullerene nanoparticles (BFNP) to aggregate over time and to compare the properties of hydroxyapatite (HAP) nanoparticles obtained through 3 different techniques. We found that aggregation of BFNP nanoparticles does not affect their function but attenuates their cytotoxicity against leukemia cells. We were also able to obtain HAP nanoparticles with programmable properties (such as size, shape or the capacity to adsorb metal ions, ligands and chemical complexes) through enzymatic synthesis by varying its conditions. The synthesized HAP nanoparticles contain short-lived isotopes of zinc and copper (in the form of ions and complexes with pyrimidine or thiazine derivatives). These tumoricidal components (a radionuclide and a ligand or a complex) determine the diagnostic and therapeutic potential of the obtained radiopharmaceutical agents.

Keywords: hydroxyapatite, porphyrin-fullerene, thiazine and pyrimidine derivatives, HL-60, K-562, MOLT-4, zinc and copper radionuclides

$\triangle$ Correspondence should be addressed: Marina A. Orlova Leninskie gory 1, bl. 3, Moscow, 119992; orlova.radiochem@mail.ru

Received: 27.06.2018 Accepted: 20.09.2018

DOI: $10.24075 / \mathrm{brsmu} .2018 .075$

Современная медицина требует новых подходов к развитию и применению лекарственных препаратов, особенно высокотоксичных антиопухолевых лекарств, так как важна их целевая доставка к биологической мишени. В связи с этим все большее внимание уделяют использованию моноклональных антител [1], биологических транспортеров [2], различных наноструктур и наноплатформ. Среди наноносителей следует выделить фуллерены [3], 
наноалмазы [4], неорганические наночастицы различной природы [5, 6], липосомы [7], пористый кремний [8], гидроксиапатиты (НАР) [9]. Разработка таких способов транспортировки лекарств преследует несколько целей: 1) снижение токсичности препарата, которая достаточно высока при прямом введении в организм. Хорошим примером понижения токсичности служит доксил доксорубицин в липосомальном контейнере [10]; 2) повышение воздействия на опухоль за счет синергического воздействия препарата и его транспортера [11]. Например, наночастицы на основе порфиринфуллерена (бакминстерфуллерен $\left(\mathrm{C}_{60}\right)$-2-(бутадиен-1-ил)-тетра(о- $\gamma$ аминобутирил-о-фталил)порфирин, или BFNP) были получены и использованы в качестве носителей магнитных изотопов ${ }^{25} \mathrm{Mg}$ и ${ }^{67} \mathrm{Zn}$, которые сами являются активными препаратами. Такая конструкция способна снижать индуцированный гипоксией ацидоз после химиотерапии [12]; 3) повышение биодоступности препарата (например, за счет связывания с альбумином), пролонгированности действия (нанофуллерены, НАР) и усиления воздействия на опухоль за счет целевого попадания в биомишень (моноклональные антитела); 4) создание конструкции, в которой и носитель, и препарат являются антиопухолевыми агентами различного действия. Например, дериватизированные фуллерены, обладающие собственным антиопухолевым действием, несут на себе магнитные изотопы или радионуклиды [13]. Этот случай реализуется при создании радиофармпрепаратов для лучевой терапии - неотьемлемой части антиопухолевой терапии.

Наночастицы НАР представляют интерес в качестве транспортеров как лекарств, так и радионуклидов, благодаря биодеградируемости, биосовместимости и оседанию (встраиванию) в костную ткань. Эти качества обусловлены их кальцийфосфатным происхождением, сходным с химическим составом минеральной части кости человека $[14,15]$.

Целью работы было исследование свойств НАР разного способа получения (и, соответственно, обладающих различными свойствами) и BFNP как потенциальных носителей ионов биологически активных металлов (в<smiles>O=C(NC1=NCCCS1)c1ccccc1</smiles>

$\left(L^{1}\right)$

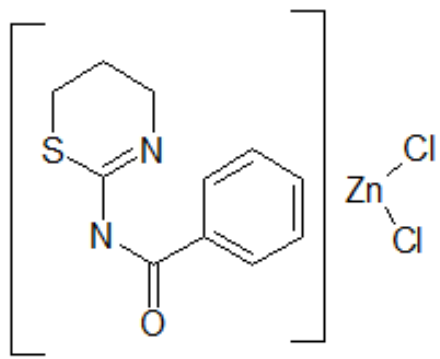

$\left(C^{1}\right)$ том числе радионуклидов) и лигандов, проявляющих антиопухолевую активность.

\section{МАТЕРИАЛЫ И МЕТОДЫ}

\section{Соединения}

Хелатор N(5,6-дигидро-4H-1,3-тиазин-2-ил)бензамид (L1) в форме гидробромида ( $\left.\mathrm{L}^{1} \mathrm{HBr}\right)$ синтезировали по методике, описанной ранее [16]. Для получения комплекса с цинком $\mathrm{L}^{1} \mathrm{ZnCl}{ }_{2}\left(\mathrm{C}^{1}\right)$ лиганд $\mathrm{L}^{1} \mathrm{HBr}$ в водном растворе переводили в форму основания (рис. 1). K основанию $L^{1}$ в диэтиловом эфире постепенно добавляли раствор хлорида цинка в диэтиловом эфире (в отношении $1: 1$ ) и перемешивали 0,5 ч. После выпадения белого осадка его выделяли в виде белого кристаллического вещества (выход 64\%). Комплекс идентифицировали методами ${ }^{1} \mathrm{H}$-ЯМР на спектрометре Bruker CXP-200 (Bruker; Германия) и элементным анализом. L² - 2-аминопиримидин (Sigma; CША), L ${ }^{3}-$ 2-аминопиримидинсалицилат. Их комплексы с цинком $\mathrm{Zn}\left(\mathrm{L}^{2}\right)_{2} \mathrm{Cl}_{2}\left(\mathrm{C}^{2}\right)$ и $\mathrm{Zn}\left(\mathrm{L}^{3}\right)_{2}\left(\mathrm{C}^{3}\right)$ получали, как описано ранее [17].

\section{Спектрофотометрия}

Измерения проводили на спектросротометре UV-1280 (Shimadzu; Япония). Калибровку по лиганду и по комплексу делали в водном, физиологическом и спиртовом растворах.

\section{Константы протонирования и устойчивости}

Константы определяли потенциометрически с помощью автотитратора Metrohm 848 Titrino plus (Metrohm AG; Швейцария). При определении константы устойчивости комплекса титрование проводили на автотитраторе со стеклянным индикаторным электродом. При расчете использовали программу Hyperquad 2013.

\section{Синтез НАР}

Метод соосаждения. Описаны способы синтеза НАР [18-20], различающиеся параметрами конечного продукта.
$\left(C^{2}\right)$

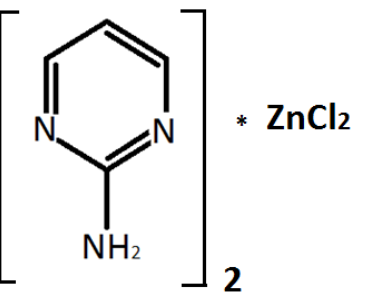<smiles>Nc1nccn1Cc1ccccc1</smiles><smiles>O=C(O[Ga]OC(=O)c1ccccc1O)c1ccccc1O</smiles> 
НАР, синтезировали при комнатной температуре и при мольном соотношении Са/Р, равном 1,67, которое соответствует стехиометрии НАР [21]. Количества всех реагентов подбирали таким образом, чтобы в итоге образовалась 5\%-я (по массе твердой фазы) суспензия продукта [22]. Остаточное содержание кальция и цинка в маточном растворе анализировали с помощью метода ICP-AES (атомно-эмиссионная спектроскопия с индуктивно связанной плазмой) на приборе Optima 2100 DV (Perkin Elmer; США). Для получения образца НАР 2 по окончании синтеза суспензию нагревали до температуры $90{ }^{\circ} \mathrm{C}$ без кипячения и выдерживали в таком режиме 44.

Ферментативный метод. Синтез НАР проводили ферментативным гидролизом глицерофосфата кальция в присутствии щелочной фоссратазы (Merk; Германия). При этом варьировали концентрацию фермента, состав среды (водная, глициновый буфер, трис-буфер), pH (7-10), концентрацию кальция и время реакции. Реакцию гидролиза глицерофосфата запускали добавлением раствора фермента к раствору глицерофоссата кальция, взятого в концентрации 0,02 моль/л. Рабочие концентрации фермента находились в интервале 0,020,4 мкг/мл. В зависимости от условий, реакцию проводили от нескольких часов до нескольких суток.

Введение ионов цинка и меди при синтезе НАР. При введении ионов металлов растворяли в $\mathrm{H}_{3} \mathrm{PO}_{4}$ навеску оксида цинка или меди (химически чистого, х. ч.), соответствующую расчетному мольному отношению $\mathrm{Zn}(\mathrm{Cu}) / \mathrm{Ca}$, равному 5 (15 мол.\%). Полученный раствор вносили по каплям в суспензию $\mathrm{Ca}(\mathrm{OH})_{2}$ при постоянном перемешивании. Продолжали синтез и получали образцы $\mathrm{HAP}_{\mathrm{zn1}}, \mathrm{HAP}_{\mathrm{zn2}}, \mathrm{HAP}_{\mathrm{Cu}}$. Небольшую часть высушенных препаратов отжигали в муфельной печи на воздухе при температуре $900{ }^{\circ} \mathrm{C}$ в течение 3 ч и исследовали методом RPA (см. ниже)

\section{Электронно-микроскопическое исследование образцов НАР}

Небольшую часть образца обрабатывали ультразвуком в ультразвуковой ванне 30 с (при частоте ультразвука 22 кГц, мощности 50 Вт). После стандартной подготовки образца использовали микроскоп JSM-6380LA (JEOL; Япония) при ускоряющем напряжении 20 кВ.

\section{Нуклиды металлов}

${ }^{69 m} \mathrm{Zn}\left(\mathrm{T}_{1 / 2}=13,7\right.$ ч; $\mathrm{E}_{\gamma}=438,7$ кэB) получали по реакции

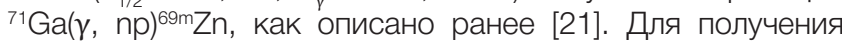
меченого соединения проводили изотопный обмен в течение 30 мин комплекса $\mathrm{C}^{1}$ в фризиологическом растворе и этиловом спирте в соотношении $1: 1$ с предварительно упаренным раствором, содержащим ${ }^{69 m} \mathrm{Zn}$ без носителя, полученным с хроматографической колонки. Для получения меченых комплексов $\mathrm{C}^{2}$ и $\mathrm{C}^{3}$ лиганды в форме оснований обрабатывали раствором ${ }^{69 \mathrm{~m}} \mathrm{ZnCl}_{2}$ при перемешивании и нагревании.

${ }^{64,67} \mathrm{Cu}\left(\mathrm{T}_{1 / 2}=12,7\right.$ ч и 61,8 ч соответственно; $\mathrm{E}_{\gamma}\left({ }^{64} \mathrm{Cu}\right)=1345,8 \mathrm{kэB}, \mathrm{E}_{\gamma}\left({ }^{67} \mathrm{Cu}\right)=184,5$ кэВ) получали по реакции ${ }^{\text {nat }} \mathrm{Zn}\left({ }_{\gamma}, \mathrm{np}\right)^{64} \mathrm{Cu}$; ${ }^{\gamma} \mathrm{za} \mathrm{Zn}(\mathrm{n}, \beta)^{67} \mathrm{Cu}$. Медь отделяли от цинка экстракцией раствором 0,001\% дитизона в $\mathrm{CCl}_{4}$, реэкстракцией в $6 \mathrm{M} \mathrm{HCl}$ и ионно-обменной хроматографией на колонке с сорбентом Cu-Resin (Triskem; Франция). Измерение радиоактивности продуктов проводили на гамма-спектрометре с полупроводниковым детектором GC 3020 (Canberra; США). ${ }^{67} \mathrm{Zn}$ и ${ }^{25} \mathrm{Mg}-$ стабильные изотопы со значениями s, равными -5/2 и $+5 / 2$ соответственно ( ${ }^{67} \mathrm{Zn}$ обогащение 94,5\%, изотопная чистота ${ }^{25} \mathrm{Mg}$ 99,9\%) («Изотоп»; Россия).

\section{Определение размера наночастиц}

Размер наночастиц определяли по методу динамического рассеяния света.

\section{Тонкослойная хроматография (TLC)}

Использовали пластины Silufol с разными элюентами. Проявление неактивной хроматограммы осуществляли парами йода.

\section{Авторадиография (ARG)}

Пластину после TLC с радиоактивными веществами характеризовали с помощью цифровой ARG, используя запасающие пластины (Storage phosphor system), покрытые BaFBr:Eu (Perkin Elmer; CША), и прибор для сканирования Cyclone Plus (Perkin Elmer; CШA).

\section{Рентгенографический фазовый анализ (RPA)}

Дифрактограммы получали на автоматизированном рентгеновском дисрактометре ДРОН-3 («Инноскоп»; Россия) с прилагаемыми программами обработки результатов. Измерения проводили на Cu-K. . Размеры кристаллитов (блоков) $D$ оценивали по формуле Шеррера:

$$
D_{\mathrm{HKL}}=\frac{\lambda}{\beta \cos \theta} .
$$

\section{Адсорбционные измерения}

Адсорбционные измерения проводили на автоматическом сорбтометре ASAP 2000 (Micromeritics; США). Расчет удельной поверхности проводили с помощью пакета программ фирмы Micromeritics, входящего в комплектацию прибора.

\section{МTT-тест}

Подробное описание процедуры представлено ранее [13]. Использовали линии клетоK HL-60, K-562, MOLT-4 и MOLT-4 (res) (res - линия клеток, резистентных к аспарагиназе, одному из основных препаратов для лечения острых лейкозов у детей), культивированные стандартным способом. Статистический анализ проводили с помощью критерия Манна-Уитни. Количество экспериментов в каждом случае было не менее пяти (с трехкратным повтором).

\section{Выделение мононуклеарных клеток из костного мозга и периферической крови}

Клетки костного мозга (КМ) пациентов с диагностированным острым В-лимфобластным лейкозом (В-ОЛЛ), острым миелоидным лейкозом (ОМЛ) или острым Т-лимфобластным лейкозом (Т-ОЛЛ) были любезно предоставлены в НМИЦ ДГОИ им. Д. Рогачева. Процедура отбора подробно описана [13]. Содержание бластных клеток в мононуклеарной фракции периферической крови составляло не менее 80\% по результатам гематологического исследования. 
Морфологические исследования производили на флуоресцентном микроскопе LEICA DM6000B (Leica Microsystems; Германия) или на лазерном сканирующем конфокальном микроскопе LSM 710 (Carl Zeiss; Германия). Изображение фиксировали с помощью видеосистемы на основе цифровой камеры.

\section{РЕЗУЛЬТАТЫ ИССЛЕДОВАНИЯ}

\section{Влияние размеров наночастиц порфиринфуллеренов на их цитотоксичность}

Результаты ряда исследований позволяют предполагать, что усиление агрегации наночастиц (фуллереновых, в частности) увеличивает величину выживаемости $\left(\mathrm{LC}_{50}\right)$, т. е. уменьшает цитотоксичность препарата [23-26]. Однако имеются и противоположные данные, в основном, для наноС $_{60}$. Мы рассмотрели влияние этого параметра на примере наночастиц BFNP.

В табл. 1 представлены данные по выживаемости линий лейкемических клеток и клеток КМ нелеченых пациентов с острыми лейкозами под действием ионов цинка (природного изотопного состава и обогащенных магнитным $\left.{ }^{67} \mathrm{Zn}\right)$, связанных с BFNP. Получена зависимость величины $L_{50}$ от размера наночастиц. Во всех случаях выживаемость клеток увеличивается с ростом агрегатов, однако направленность действия препаратов не меняется.

Обработка ультразвуком приводила к уменьшению среднего размера наночастиц до 15-20 нм, однако, как показали эксперименты, через неделю средний размер составлял 20-30 нм, через 2 недели - 30-40 нм, через месяц - 50-60 нм.

Морфологические исследования показали, что не только наночастицы, но и клетки, обработанные BFNP с магнитным изотопом цинка, подвержены усиленной агрегации (данные не представлены).

\section{Воздействие на клетки лигандов, потенциально перспективных для нанесения на НАР}

Потенциальными хелаторами (антиопухолевыми агентами), предлагаемыми для нанесения на наночастицы НАР, могут быть как лиганды, так и их комплексы с ионами металлов, в частности с ионами цинка и меди (которые в перспективе могут быть заменены или обменены на короткоживущие радионуклиды с получением радиофармпрепаратов). Вещества могут наноситься на НАР как в виде комплекса, так и по отдельности в виде ионов металла и лигандахелатора. В обоих случаях комплекс или его компоненты будут действовать либо синергически, либо по отдельности.

В табл. 2 представлены результаты выживаемости клеток линии K-562 под действием лиганда L ${ }^{1}$ и комплексов в сравнении с клетками нормальных лимфоцитов здоровых доноров (ЗД). На нормальных лимфоцитах и линиях клеток MOLT-4 и MOLT-4 (res) показана очень высокая выживаемость клеток под действием различных образцов НАР, в том числе содержащих ионы металлов цинка и меди.

Для исследованных хелаторов и комплексов характерны тенденции к увеличению (уменьшению) цитотоксичности по

Таблица 1. Значения выживаемости ( $\left.\mathrm{LC}_{50}\right)$ лейкемических клеток различной природы в сравнении с нормальными лимфоцитами под действием Zn-BFNP и ${ }^{67} \mathrm{Zn}-\mathrm{BFNP}$ и в зависимости от размера наночастиц

\begin{tabular}{|c|c|c|c|}
\hline \multirow{2}{*}{ Препарат } & \multicolumn{3}{|c|}{$\mathrm{LC}_{50}, \mathrm{Mкг} / \mathrm{M} л$} \\
\hline & В-Олл & ОМл & ЗД* \\
\hline Zn- BFNP & $60 \pm 8$ & $64 \pm 3$ & $81 \pm 9$ \\
\hline${ }^{67} \mathrm{Zn}-\mathrm{BFNP}$ & $16 \pm 3$ & $63 \pm 8$ & $79 \pm 9$ \\
\hline \multicolumn{4}{|c|}{ Средний размер наночастиц и $\mathrm{LC}_{50}$} \\
\hline Zn- BFNP & $25 \mathrm{HM}$ & $55 \mathrm{HM}$ & \\
\hline${ }^{67} \mathrm{Zn}-\mathrm{BFNP}$ & $37 \pm 3$ мкг/Мл & $78 \pm 6$, мкг/мл & \\
\hline \multicolumn{4}{|c|}{ Средний размер наночастиц и $\mathrm{LC}_{50}$} \\
\hline $\mathrm{Zn}$ - BFNP & $50 \mathrm{HM}$ & $80 \mathrm{HM}$ & \\
\hline${ }^{67} \mathrm{Zn}-\mathrm{BFNP}$ & $10 \pm 2$ мкг/мл & $23 \pm 3$ мкг/мл & \\
\hline
\end{tabular}

Примечание: *ЗД — нормальные лимфоциты здоровых доноров.

Таблица 2. Зависимость выживаемости ( $\left.\mathrm{LC}_{50}\right)$ различных клеток под действием солей цинка, хелаторов и НАР различной структуры

\begin{tabular}{|c|c|c|c|c|c|c|}
\hline \multirow{2}{*}{ Препараты } & \multicolumn{6}{|c|}{$\mathrm{LC}_{50}$, мкмоль/мл } \\
\hline & Клетки ЗД & K-562 & MOLT-4 & MOLT-4 (res) & $\mathrm{HL}-60$ & В-ОЛЛ* \\
\hline $\mathrm{ZnCl}_{2}{ }^{* *}$ & $1,6 \pm 0,3$ & $0,52 \pm 0,05$ & & & & \\
\hline $\mathrm{ZnSal}_{2}\left(\mathrm{H}_{2} \mathrm{O}\right)_{2}{ }^{* *}$ & $0,68 \pm 0,06$ & $0,41 \pm 0,05$ & & & & \\
\hline $\mathrm{C}^{3}$ & $1,0 \pm 0,2$ & $0,25 \pm 0,04$ & & & & \\
\hline $\mathrm{L}^{1}$ & $10,6 \pm 0,5$ & $1,0 \pm 0,3$ & & & & \\
\hline $\mathrm{C}^{1}$ & $4,5 \pm 0,4$ & $1,1 \pm 0,2$ & & & & \\
\hline $\mathrm{C}^{2}$ & $0,24 \pm 0,04$ & $0,12 \pm 0,02$ & $0,062 \pm 0,008$ & $0,040 \pm 0,009$ & $0,039 \pm 0,009$ & $0,061 \pm 0,007$ \\
\hline $\mathrm{HAP}_{1}$ & $>>5 \cdot 10^{-3}$ моль/л & & 3,5 • $10^{-3}$ моль/л & $>5 \cdot 10^{-3}$ моль/л & & \\
\hline $\mathrm{HAP}_{2}$ & $>5 \cdot 10^{-3}$ моль/л & & $4 \cdot 10^{-3}$ моль/л & $>5 \cdot 10^{-3}$ моль/л & & \\
\hline $\mathrm{HAPZn}_{1}$ & $>5 \cdot 10^{-3}$ моль/л & & $>5 \cdot 10^{-3}$ моль/л & $>5 \cdot 10^{-3}$ моль/л & & \\
\hline $\mathrm{HAPZn}_{2}$ & $>>5 \cdot 10^{-3}$ моль/л & & $>>5 \cdot 10^{-3}$ моль/л & 6,5 • $10^{-3}$ моль/л & & \\
\hline $\mathrm{HAP}_{\mathrm{Cu}}$ & $>>5 \cdot 10^{-3}$ моль/л & & $>>5 \cdot 10^{-3}$ моль/л & $5 \cdot 10^{-3}$ моль/л & & \\
\hline
\end{tabular}

Примечание: * - В-ОЛЛ — клетки КМ пациентов с диагнозом острый В-лимсобластный лейкоз; ** — по данным [17]. 
отношению к нормальным лимсоцитам и раковым клеткам. Среди клеток здоровых доноров выживаемость снижается в следующей последовательности: $\mathrm{L}^{1}>\mathrm{C}^{1}>\mathrm{ZnCl}_{2}>\mathrm{C}^{3}>$ $\mathrm{ZnSal}_{2}\left(\mathrm{H}_{2} \mathrm{O}\right)_{2}>\mathrm{C}^{2}$. По отношению к линии хронического миелолейкоза К-562 эта последовательность изменяется: $\mathrm{C}^{1}>\mathrm{L}^{1}>\mathrm{ZnCl}_{2}>\mathrm{ZnSal}_{2}\left(\mathrm{H}_{2} \mathrm{O}\right)_{2}>\mathrm{C}^{3}>\mathrm{C}^{2}$. Величина терапевтического окна, или терапевтического индекса (ТИ $=L_{50}$ (ЗД)/LC ${ }_{50}$ (лейкемические клетки)), уменьшается в ряду: $\mathrm{L}^{1}>\mathrm{C}^{3} \sim \mathrm{C}^{1}>\mathrm{ZnCl}_{2}>\mathrm{C}^{2}>\mathrm{ZnSal}_{2}\left(\mathrm{H}_{2} \mathrm{O}\right)_{2}$. Таким образом, все три комплекса представляют интерес в качестве антиопухолевых агентов.

При сравнении воздействия комплекса $\mathrm{C}^{2}$ на различные линии клеток и клетки КМ пациентов с В-ОЛЛ получили следующую последовательность: клетки ЗД > К-562 > HL-60 MOLT-4 (res) > MOLT-4 KM (В-ОЛЛ). Важно, что $\mathrm{C}^{2}$ более цитотоксичен по отношению к клеткам MOLT4 (res), по сравнению с линией обычных клеток MOLT-4. Таким образом, наблюдается специфичность к клеткам, вызывающим наибольшие осложнения при химиотерапии (рис. 2).

Важной характеристикой лигандов и комплексов является их устойчивость, особенно в водном/ физиологическом растворе. $\mathrm{K}$ сожалению, чаще встречаются биологически активные лиганды-хелаторы и комплексы, плохо растворимые в воде. Для них требуется обязательный носитель или специальная упаковка при введении в организм. Частично эту функцию может выполнять НАР.

Спектрофотометрические исследования устойчивости комплексов в водных, спиртовых и физиологичесих растворах показали, что наименее устойчив комплекс $\mathrm{C}^{1}$ : через некоторое время он гидролизуется с образованием тиазина (который, однако, также проявляет слабые антиопухолевые и высокие радиопротекторные свойства). Остальные комплексы были достаточно устойчивы в течение времени после разведения, необходимого для применения в медицинских целях.

Метод потенциометрического титрования лиганда $L^{1}$, проведенный в водном и физиологическом растворах в зависимости от $\mathrm{pH}$ (при $\mathrm{C}\left(\mathrm{L}^{1}\right)=1 \cdot 10^{-3}$ моль/л, I = 0,15 NaCl (0,1 моль/л $\left.\left.\mathrm{KNO}_{3}\right)\right)$, показал, что константы протонирования равны $\log K=5,1 \pm 0,1$ (водный раствор) и $\log K=5,3 \pm 0,2$ (физиологический раствор). Попытка потенциометрически определить константу устойчивости комплекса $\mathrm{C}^{1}$ не принесла успеха. Это может быть связано с образованием гидроксида цинка, мешающим проведению титрования. Для комплекса $\mathrm{C}^{2}$ константа устойчивости составляла $\log K\left(C^{2}\right)=10,4 \pm 0,5$.

\section{Поведение наноНАР, несущих лиганды, ионы металлов и/или комплексы}

На рис. 3 (А, Б) показано поведение (сорбция) лиганда $L^{1}$ на HAP1 и НАР2. Изменения наблюдаются только в первый момент сорбции, вероятно, за счет взаимодействия с некоторым количеством кальция в суспензии, появляющимся за счет растворения наноНАР. Это значит, что лиганд $L^{1}$ не связывается с гидроксиапатитом. Аналогичную картину можно наблюдать и для $\mathrm{L}^{2}$ и $\mathrm{L}^{3}$.

Метод электронной микроскопии дает возможность представить морфологию нанокристаллов, а рентгеновские дисрактограммы позволяют оценить состав твердой фазы, соответствующий биогидроксиапатиту. Для НАР эти результаты представлены на рис. 4. Средние размеры для цинк-содержащих и «чистых» наночастиц показывают уменьшение размеров в случае термообработки, которое значительно для «чистых» и практически незначимо для цинк-содержащих наночастиц (табл. 3).

Для $\mathrm{HAP}_{\mathrm{E}}$ (рис. 5A) показано образование гидроксиапатита в качестве основной фазы (рис. 5Б) и наблюдается сферическая форма наночастиц, образующих микроагрегаты. Удельная поверхность образца, определенная по адсорбции азота, составляла 300 м²/г. При этом наблюдалось широкое распределение пор по размерам (2-300 нм). Размеры кристаллитов в образцах, имеющих кристаллическую структуру, оценивали по формуле Шеррера. Их размер составил 12-14 нм. Наблюдали большую разницу в размерах кристаллитов и агрегатов, средние размеры которых показаны на рис. 6.

A

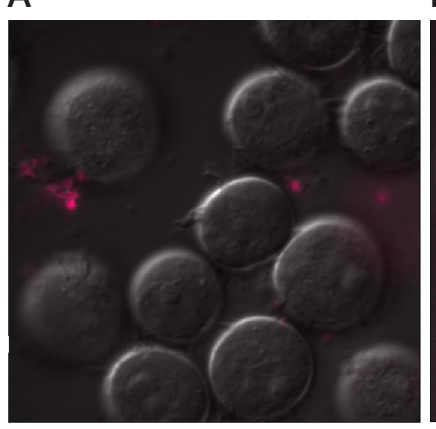

Б

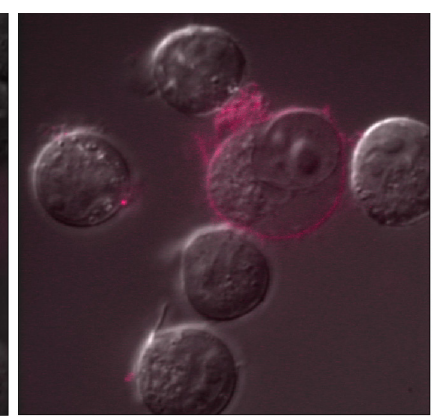

Рис. 2. Клетки MOLT-4 под действием соединений $L^{3}$ (А) и $C^{3}$ (Б). Снимки сделаны на конфокальном микроскопе

A
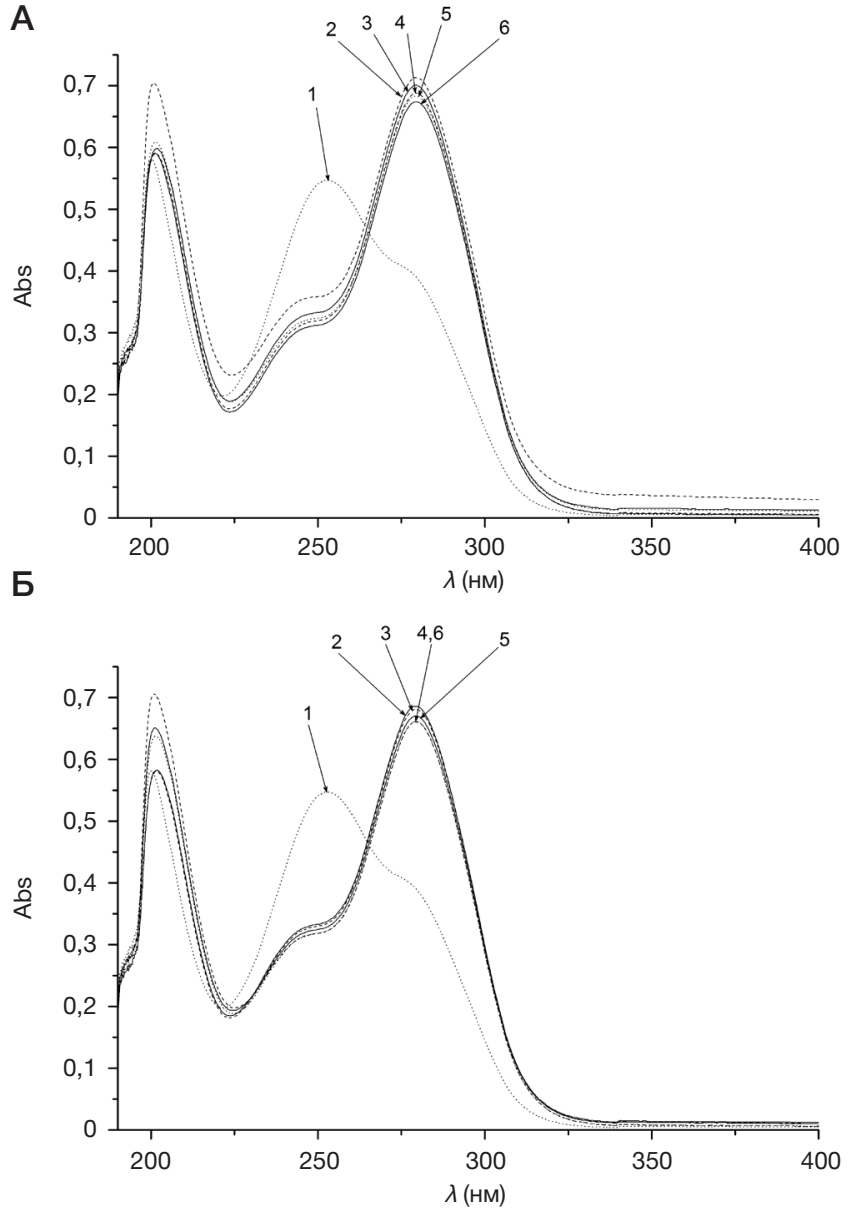

Рис. 3. Спектры поглощения, полученные для $10^{-2}$ мг/мл раствора $L^{1}$, находящегося в контакте с НАР $($ (А) и НАР $($ (Б) в течение 0 мин (1), 5 мин (2), $10 \mathrm{Mин} \mathrm{(3),} 15 \mathrm{мин} \mathrm{(4),} 30 \mathrm{Mин} \mathrm{(5),} 60 \mathrm{Mин} \mathrm{(6)}$ 
В работе использовали шесть различных форм НАР: не содержащие ионы металлов $\mathrm{HAP}_{1}, \mathrm{HAP}_{2}, \mathrm{HAP}_{\mathrm{E}}$, а также $\mathrm{HAP}_{\text {zn1 }}, \mathrm{HAP}_{\text {Zn2 }}, \mathrm{HAP}_{\mathrm{Cu}}$. HAPE отличался сферической формой (сферы полые), большими размерами и увеличенными сорбционными свойствами. Средние размеры остальных располагаются в следующем ряду: $\mathrm{HAP}_{1}>\mathrm{HAP}_{\mathrm{Zn1}}>\mathrm{HAP}_{\mathrm{Zn2}} \sim \mathrm{HAP}_{\mathrm{Cu}}>\mathrm{HAP}_{2}$

Были получены величины удельной адсорбции ионов цинка и меди на НАР, и НАР адсорбции по Ленгмюру и Фрейндлиху. Сорбция ионов меди полностью соответствует модели Ленгмюра, а ионов цинка с равными коэффициентами корреляции соответствует моделям и Ленгмюра, и Фрейдлиха.

Сорбционная емкость НАР по отношению к ионам меди оказалась значительно выше, чем к ионам цинка. Введение цинка мало влияет на размеры частиц. Однако средние размеры термически обработанного НАР 2 меньше, чем у $\mathrm{HAP}_{1}$. Частицы НАР 2 приобретают более правильную изометрическую форму (увеличивается их толщина) по сравнению с НАР поверхности. Как результат, максимальная сорбционная емкость для $\mathrm{HAP}_{2}$ уменьшается.

\section{Комплексы с радионуклидами цинка и меди}

C помощью изотопного обмена были получены $69 \mathrm{~m} Z \mathrm{nC}$ (I), ${ }^{69 m \mathrm{ZnC}^{3}}$ (II) и $\left[\left(\mathrm{L}^{2}\right)_{2}{ }^{64,67} \mathrm{CuCl}_{4}\right]$ (III) и охарактеризовань методами TLC, ARG и $\gamma$-спектрометрией. Время изотопного обмена подбирали экспериментально, чтобы величины $R_{\mathrm{f}}$ радиопрепаратов совпадали с таковыми для препаратов без радионуклида и не образовывалось побочных продуктов. После этого полученные соединения сорбировали на НАР и проводили повторно физикохимические измерения. Готовые радиопрепараты имели аналогичные свойства, однако комплекс с медью при «посадке» на НАР 1 разлагался. В этом случае наноНАР сорбировал только ионы меди. Возможно, эту проблему можно будет решить введением комплекса в НАР непосредственно в процессе его синтеза.

A

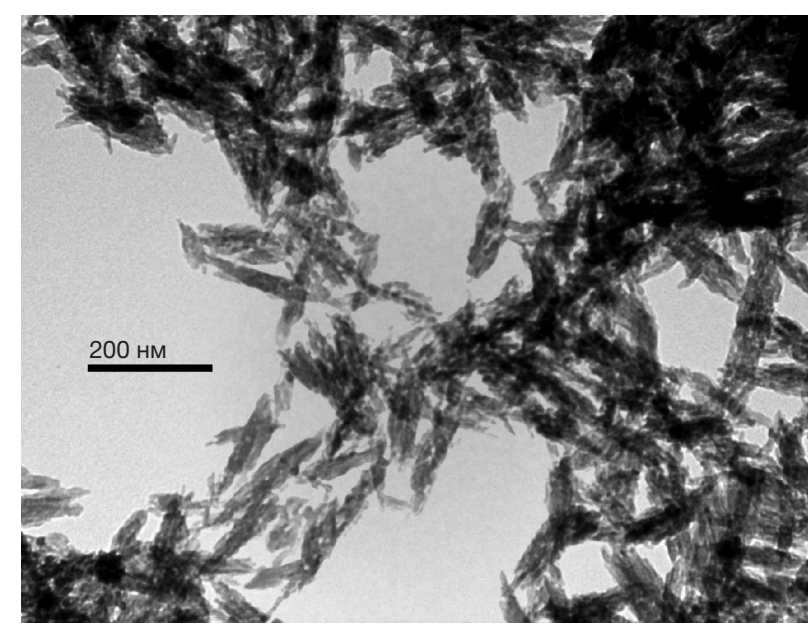

\section{ОБСУЖДЕНИЕ РЕЗУЛЬТАТОВ}

Ранее было показано, что магнитный изотоп ${ }^{25} \mathrm{Mg}$ (доля В природной смеси изотопов равна 11\%) является гиперактивирующим элементом магний-зависимого контроля синтеза АТФ, что делает направленную доставку этого изотопа к пораженным гипоксией клеткам/ тканям перспективной фармакологической задачей [12]. Наночастицы BFNP, способные к пролонгированному выпуску ионов $\mathrm{Mg}^{2+}$ и $\mathrm{Zn}^{2+}$, могут служить средством такой доставки. Однако основным сдерживающим фактором для клинического применения любых фуллереновых производных является возможная неконтролируемая агрегация наночастиц с изменением их первоначальных цитотоксических и физиологических свойств. Приведенные в нашей работе данные показывают, что происходящие изменения размеров не ведут $\mathrm{K}$ принципиальным изменениям свойств частиц, хотя и уменьшают степень их воздействия на опухолевые клетки. Таким результатом является уменьшение примерно в 6-7 раз выживаемости клеток КМ нелеченых пациентов с диагнозом В-ОЛЛ

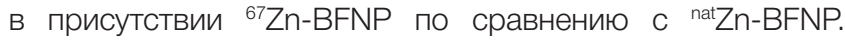
Использование предварительной ультразвуковой обработки способно замедлить агрегацию.

Наночастицы НАР имеют богатую перспективу применения для drug delivery, так как могут быть синтезированы различными способами, что дает в результате частицы с разными характеристиками по размерам, форме и их сорбционным свойствам. Кроме того, они обладают очень низкой цитотоксичностью. Введение лигандов и комплексов непосредственно в процесс синтеза, вероятно, является более удачным приемом, сохраняющим свойства всех компонентов соединения. Особенно перспективным выглядит ферментативный способ получения носителя, так как в этом случае возможны вариации условий, приводящие к сильно различающимся параметрам частиц. Это расширяет возможности их применения.

Микроэлементы имеют большое значение для нормального функционирования организма. Среди них

Б

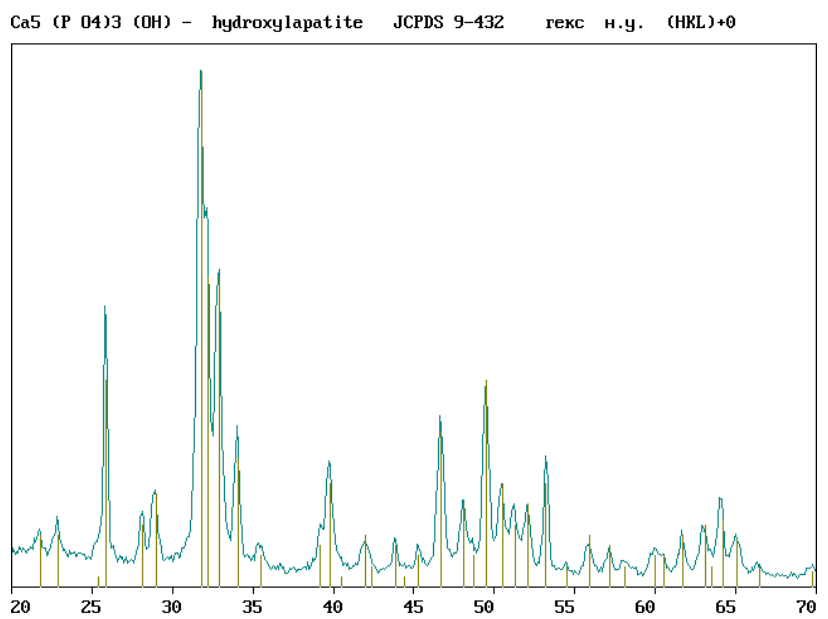

Рис. 4. Электронная микрофотография (А) и рентгеновская дифрактограмма (Б) образца НАР1, синтезированного из суспензии оксида кальция и фосфорной кислоты

Таблица 3. Средние размеры наночастиц неферментативного НАР и НАР, допированного цинком

\begin{tabular}{|c|c|c|c|c|}
\hline Параметр & $\mathrm{HAP}_{1}$ & $\mathrm{HAP}_{\mathrm{Zn} 1}$ & $\mathrm{HAP}_{\mathrm{Zn} 2}$ & $\mathrm{HAP}_{2}$ \\
\hline Длина, $\mathrm{HM}$ & $120 \pm 5$ & $110 \pm 5$ & $98 \pm 4$ & $56 \pm 2$ \\
\hline Ширина, нм & $36 \pm 3$ & $23 \pm 2$ & $26 \pm 2$ & $19 \pm 1$ \\
\hline
\end{tabular}


A

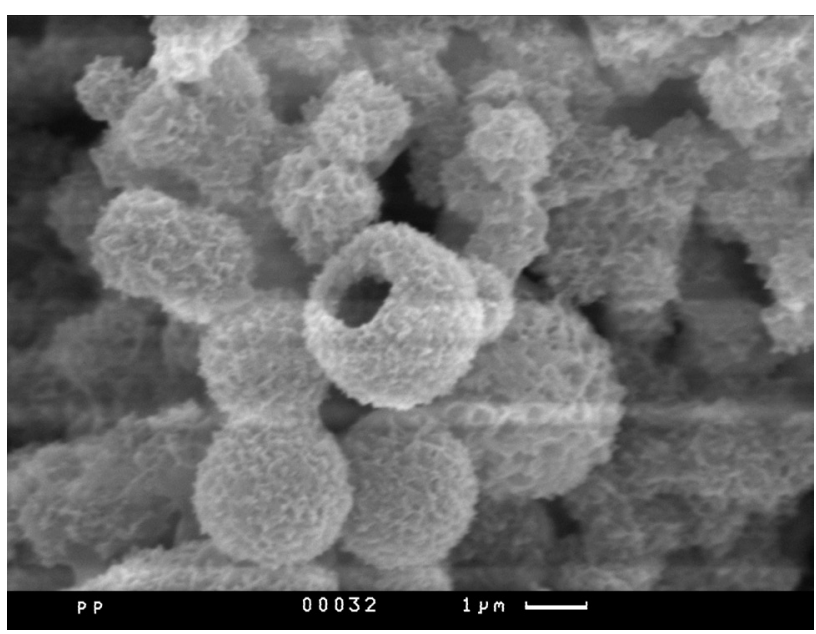

5

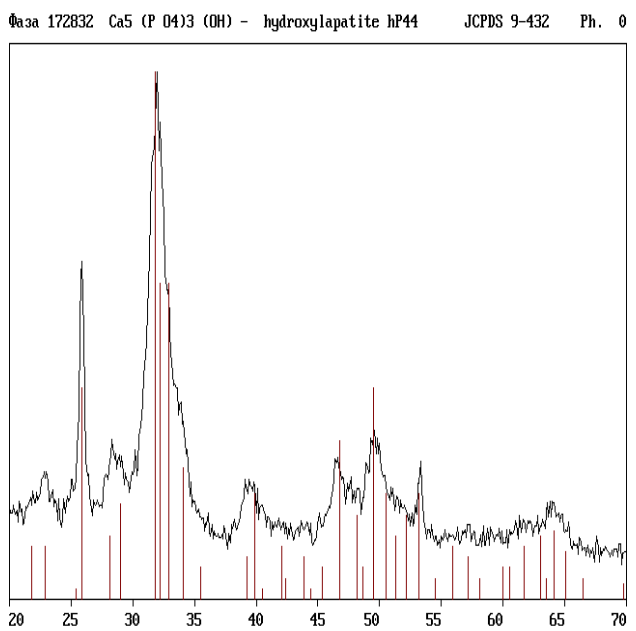

Рис. 5. Данные сканирующей электронной микроскопии (А) и рентгенофазового анализа (Б) образца (НАР $)$, синтезированного из водного раствора глицерофосфата кальция (0,2 моль/л) при концентрации щелочной фосфатазы 0,1 мкг/мл

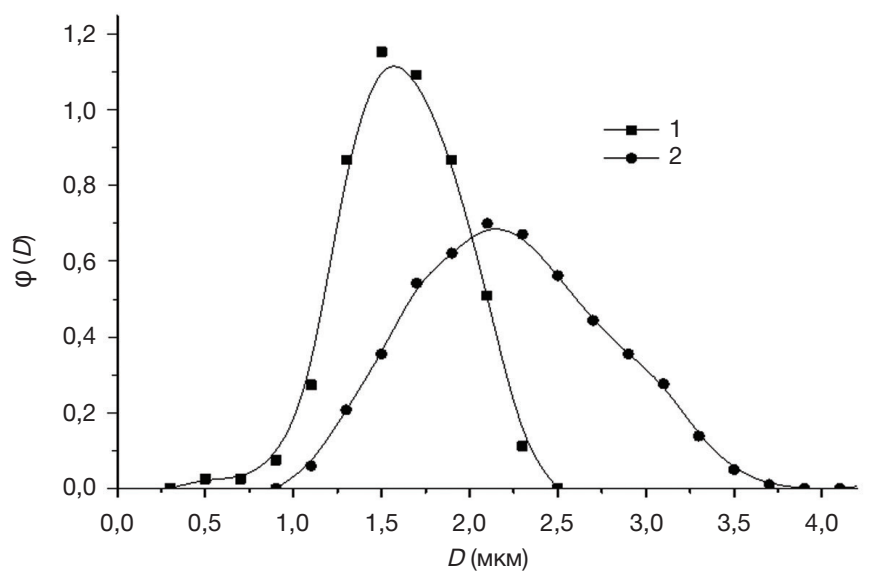

Рис. 6. Дифференциальная функция распределения по диаметру микрочастиц образца, синтезированного в трис-бусрере (рН = 9,2) при добавлении щелочной фосфатазы в концентрации: 1) 0,02 мкг/мл (средний размер частиц 1,57 мкм); 2) 0,1 мкг/мл (средний размер частиц 2,22 мкм)

важнейшая роль принадлежит цинку и меди [27, 28]. Они являются кофакторами большинства регуляторных и антиоксидантных ферментов, включены в работу репаративной системы и транскрипционных факторов. Поэтому появление комплексов, содержащих короткоживущие радионуклиды этих микроэлементов, позволяет решать задачи по диагностике и терапии по отдельности и совместно. НАР может служить подложкой, обеспечивающей совместное пролонгированное действие конструкции. Как правило, для этого требуется вектор, в качестве которого оптимальны моноклональные антитела. Однако НАР сам может встраиваться в кость и костную ткань, и тогда выступает вектором доставки радиосармпрепарата. Этот процесс может иметь значение при лечении онкологических заболеваний костной ткани и злокачественных нарушениях кроветворения на уровне стволовых раковых клеток.

Удельная активность радиопрепаратов в данной работе была невысокой, поскольку эксперименты имели предварительный характер и должны были показать возможность создания и использования таких комплексов в разумный для применения в медицинских целях период времени. Имеются резервы для создания соединений большей удельной радиоактивности.

\section{ВЫВОДЫ}

Изменение размеров ${ }^{67} \mathrm{Zn}$-BFNP вследствие агрегации качественно не влияло на функцию наночастиц, но количественно уменьшало воздействие на лейкемические клетки. Варьирование способов получения и обработки наночастиц НАР позволяет менять их сорбционную способность по отношению к ионам металлов и к лигандам и комплексам. НАР заданными свойствами путем варьирования условий синтеза. Получены наночастицы НАР, представляющие собой радиопрепараты, содержащие короткоживущие изотопы цинка и меди (в виде ионов и соединений). Эти наноконструкции представляют интерес для применения при решении задач диагностики и лучевой терапии. 


\section{Литература}

1. Karachunskie Al, Rumyantseva YuV, fon Shtakelberg A. AntiCD19 monoclonal antibody in acute lymphoblastic leukemia in children. Russ J Pediatric Hematol Oncol. 2016; 3 (4): 60-72. DOI: 10.21682/2311-1267-2016-3-4-60-72.

2. Lee $Y$, Lin $Y$, Lima C. Factors Controlling the Role of $Z n$ and Reactivity of $\mathrm{Zn}$-bound Cysteines in Proteins: Application to Drug Target Discovery. J Chin Chem Soc. 2014; 61 (1): 142-50. DOI: 10.1002/jccs.201300392

3. Chen Z, Ma L, Liu Y, Chen C. Applications of Functionalized Fullerenes in Tumor Theranostics. Theranostics. 2012; 2 (3): 23850. DOI: 10.7150/thno.3509.

4. Mochalin VN, Shenderova O, Ho D, Gogotsi Y. The properties and applications of nanodiamonds. Nature Nanotechnol. 2011; 7 (1) 11-23. DOI: 10.1038/nnano.2011.209.

5. Meshalkin YP, Bgatova NP. Prospects and problems of using inorganic nanoparticles in oncology. J Siber Fed Univ Biol. 2008; 3 (1): 248-68.

6. Nunes C, Estevez SV, Chantada MP. Inorganic nanoparticles in diagnosis and treatment of breast cancer. J Biol Inorg Chem. 2018; (23): 331-45. DOl: org/10.1007/s00775-018-1542-z.

7. Lasis DD, Papahadjopoulos D, editors. Medical Applications of Liposomes. USA: Elsevier Sci, 2007; 779 p. DOI: 1016/B978-0444-82917-7.X5000-5.

8. Haidary SM, Corcoles EP, Ali NK. Nanoporous Silicon as Drug Delivery Systems for Cancer Therapies. J Nanomater. 2012; ID 830503:15. DOI: 10.1155/2012/830503.

9. Ferraz MP, Monteiro FJ, Manuel CM. Hydroxyapatite nanoparticles: A review of preparation methodologies. J Appl Biomater Biomechanics. 2004; 2 (2): 74-80.

10. Zhao Y, Alakhova DY, Kim JO, Bronich TK, Kabanov AV. A simple way to enhance Doxil therapy: Drug release from liposomes at the tumor site by amphiphilic block copolymer. J Control Release. 2013; 168 (1): 61-9. DOI: 10.1016/j.jconrel.2013.02.026.

11. Liu JH, Cao L, Luo PG et al. Fullerene-conjugated doxorubicin in cells. Acs Appl Mater Interf. 2010; (2): 1384-9.

12. Buchachenko AL, Kouznetsov DA, Breslavskaya NN, Orlova MA Magnesium Isotope Effect in Enzymatic Phosphorylation. J Phys Chem. 2008; (112): 2548-56.

13. Orlova MA, Osipova EY, Roumiantsev SA. Effect of $67 \mathrm{Zn}$ Nanoparticles on Leukemic Cells and Normal Lymphocytes. $\mathrm{Br} J$ Med Med Res. 2012; 2 (1): 21-30. DOl: 10.9734/ BJMMR/2012/783

14. Sun F, Zhou H, Lee J. Various preparation methods of highly porous hydroxyapatite/polymer nanoscale biocomposites for bone regeneration. Acta Biomaterialia. 2011; 7 (11): 3813-28. DOI: 10.1016/j.actbio.2011.07.002.

15. Hutmacher DW, Schantz JT, Lam CXF, Tan KC, Lim TC. State of the art and future directions of scaffold-based bone engineering from a biomaterials perspective. J Tissue Eng Regenerative Med. 2007; 1 (4): 245-60. DOI: 10.1002/term.24.

16. Orlova MA, Trofimova TP, Aliev RA, Orlov AP, Nikulin SV, Kalmykov SN et al. 69mZn-containing radiopharmaceuticals. A novel approach to molecular design. J Radioanal Nucl Chem. 2017; 311 (2): 1177-83. DOI: 10.1007/s10967-016-5076-y.

17. Орлов А. П., Орлова М. А., Трифонова Т. П., Осипова Е. Ю., Прошин А. Н. Действие салицилатов и солей цинка на лейкемические клетки. Известия АН, Серия химия. 2016; 65 (7): 1879-81. DOI: 10.1007/s11172-016-1525-6.

18. Safronova EV, Putlyaev VI, Sergeeva Al, Kunenkov EV, Tretyakov YD. Synthesis of Nanocrystalline Calcium Hydroxyapatite from Calcium Saccharates and Ammonium Hydrogen Phosphate. Doklady Chem. 2009; 426 (2): 118-23. DOI: 10.1134/S0012500809060020.

19. Thian ES, Konishi T, Kawanobe Y, Lim PN, Choong C, Ho B, Aizawa M. Zinc-substituted hydroxyapatite: a biomaterial with enhanced bioactivity and antibacterial properties. J Mater Sci: Mater Med. 2013; 24 (2): 437-45. DOI: 10.1007/s10856-0124817-x.

20. Tang Y, Chappell HF, Dove MT, Reeder RJ, Lee YJ. Zinc incorporation into hydroxylapatite. Biomaterials. 2009; 30 (15): 2864-2872. DOI: 10.1016/j.biomaterials.2009.01.043.

21. Severin AV, Pankratov DA. Synthesis of nanohydroxyapatite in the presence of iron (III) ions. Russ J Inorg Chem. 2016; 61 (1): 265-72.

22. $\mathrm{Xu} Y$, Schwartz FW, Traina SJ. Sorption of Zn2+ and Cd2+ on Hydroxyapatite Surfaces. Envir Sci Technol. 1994; 28 (8): 1472-80.

23. Markovic Z, Trajkovic V. Biomedical potential of the reactive oxygen species generation and quenching by fullerenes (C60). Biomaterials, 2008; (29): 3561-73.

24. Fortner JD, Lyon DY, Sayes CM, Boyd AM, Falkner JC, Hotze EM et al. C-60 in water: nanocrystal formation and microbial response. Environ Sci Technol. 2005; (39): 4307-16.

25. Colvin VL. The potential environmental impact of engineered nanomaterials. Nat Biotechnol. 2003; (21): 1166-70.

26. Sayes CM, Gobin AM, Ausman KD, Mendez J, West J, Colvin VL. Nano-C60 cytotoxicity is due to lipid peroxidation. Biomaterials. 2005; (26): 7587-95.

27. Colvin RA, Holmes WR, Fontainea CP, Maret W. Cytosolic zinc buffering and muffling: their role in intracellular zinc homeostasis. Metallomics. 2010; 2 (2): 306-17.

28. Du Y, Guo D, Wu Q, Liu D, Bi H. Zinc Chloride Inhibits Human Lens Epithelial Cell Migration and Proliferation Involved in TGF- $\beta 1$ and TNF- $\alpha$ Signaling Pathways in HLE B-3 Cells. Biol Trace Elem Res. 2014; 159 (4): 425-43. DOI: 10.1007/s12011-014-9979-6.

2018; (23): 331-45. DOl: org/10.1007/s00775-018-1542-z.

7. Lasis DD, Papahadjopoulos D, editors. Medical Applications of Liposomes. USA: Elsevier Sci, 2007; 779 p. DOI: 1016/B978-0444-82917-7.X5000-5.

8. Haidary SM, Corcoles EP, Ali NK. Nanoporous Silicon as Drug Delivery Systems for Cancer Therapies. J Nanomater. 2012; ID 830503:15. DOI: 10.1155/2012/830503.

9. Ferraz MP, Monteiro FJ, Manuel CM. Hydroxyapatite nanoparticles: A review of preparation methodologies. J Appl Biomater Biomechanics. 2004; 2 (2): 74-80.

10. Zhao Y, Alakhova DY, Kim JO, Bronich TK, Kabanov AV. A simple way to enhance Doxil therapy: Drug release from liposomes at the tumor site by amphiphilic block copolymer. J Control Release. 2013; 168 (1): 61-9. DOI: 10.1016/j.jconrel.2013.02.026.

11. Liu JH, Cao L, Luo PG et al. Fullerene-conjugated doxorubicin in cells. Acs Appl Mater Interf. 2010; (2): 1384-9.

12. Buchachenko AL, Kouznetsov DA, Breslavskaya NN, Orlova MA. Magnesium Isotope Effect in Enzymatic Phosphorylation. J Phys Chem. 2008; (112): 2548-56. 
13. Orlova MA, Osipova EY, Roumiantsev SA. Effect of 67ZnNanoparticles on Leukemic Cells and Normal Lymphocytes. Br J Med Med Res. 2012; 2 (1): 21-30. DOl: 10.9734/ BJMMR/2012/783.

14. Sun F, Zhou H, Lee J. Various preparation methods of highly porous hydroxyapatite/polymer nanoscale biocomposites for bone regeneration. Acta Biomaterialia. 2011; 7 (11): 3813-28. DOI: 10.1016/j.actbio.2011.07.002.

15. Hutmacher DW, Schantz JT, Lam CXF, Tan KC, Lim TC. State of the art and future directions of scaffold-based bone engineering from a biomaterials perspective. J Tissue Eng Regenerative Med. 2007; 1 (4): 245-60. DOI: 10.1002/term.24.

16. Orlova MA, Trofimova TP, Aliev RA, Orlov AP, Nikulin SV, Kalmykov $\mathrm{SN}$ et al. $69 \mathrm{mZn}$-containing radiopharmaceuticals. A novel approach to molecular design. J Radioanal Nucl Chem. 2017; 311 (2): 1177-83. DOI: 10.1007/s10967-016-5076-y.

17. Orlov AP, Orlova MA, Trofimova TP, Osipova EY, Proshin AN. Effect of salicylates and zinc salts on leukemic cells. Russ Chem Bull. 2016; 65 (7): 1879-81. DOI: 10.1007/s11172-016-1525-6.

18. Safronova EV, Putlyaev VI, Sergeeva Al, Kunenkov EV, Tretyakov YD. Synthesis of Nanocrystalline Calcium Hydroxyapatite from Calcium Saccharates and Ammonium Hydrogen Phosphate. Doklady Chem. 2009; 426 (2): 118-23. DOI: 10.1134/S0012500809060020.

19. Thian ES, Konishi T, Kawanobe Y, Lim PN, Choong C, Ho B, Aizawa M. Zinc-substituted hydroxyapatite: a biomaterial with enhanced bioactivity and antibacterial properties. J Mater Sci: Mater Med. 2013; 24 (2): 437-45. DOI: 10.1007/s10856-0124817-x.
20. Tang Y, Chappell HF, Dove MT, Reeder RJ, Lee YJ. Zinc incorporation into hydroxylapatite. Biomaterials. 2009; 30 (15): 2864-2872. DOI: 10.1016/j.biomaterials.2009.01.043.

21. Severin AV, Pankratov DA. Synthesis of nanohydroxyapatite in the presence of iron (III) ions. Russ J Inorg Chem. 2016; 61 (1): 265-72.

22. Xu Y, Schwartz FW, Traina SJ. Sorption of Zn2+ and Cd2+ on Hydroxyapatite Surfaces. Envir Sci Technol. 1994; 28 (8): 147280.

23. Markovic Z, Trajkovic V. Biomedical potential of the reactive oxygen species generation and quenching by fullerenes (C60). Biomaterials, 2008; (29): 3561-73.

24. Fortner JD, Lyon DY, Sayes CM, Boyd AM, Falkner JC, Hotze EM et al. C-60 in water: nanocrystal formation and microbial response. Environ Sci Technol. 2005; (39): 4307-16.

25. Colvin VL. The potential environmental impact of engineered nanomaterials. Nat Biotechnol. 2003; (21): 1166-70.

26. Sayes CM, Gobin AM, Ausman KD, Mendez J, West J, Colvin VL. Nano-C60 cytotoxicity is due to lipid peroxidation. Biomaterials. 2005; (26): 7587-95.

27. Colvin RA, Holmes WR, Fontainea CP, Maret W. Cytosolic zinc buffering and muffling: their role in intracellular zinc homeostasis. Metallomics. 2010; 2 (2): 306-17.

28. Du Y, Guo D, Wu Q, Liu D, Bi H. Zinc Chloride Inhibits Human Lens Epithelial Cell Migration and Proliferation Involved in TGF- $\beta 1$ and TNF- $\alpha$ Signaling Pathways in HLE B-3 Cells. Biol Trace Elem Res. 2014; 159 (4): 425-43. DOI: 10.1007/s12011-014-9979-6. 